\section{Anaphylaxis due to Perioperative Intravenous Lidocaine}

Carrión Sari SK, Lezaun A, Colas Sanz C

Hospital Clínico Universitario Lozano Blesa IIS-Aragón, Zaragoza, Spain

J Investig Allergol Clin Immunol 2021; Vol. 31(2): 164-165 doi: 10.18176/jiaci.0626

Key words: Anaphylaxis. Allergy. Local anesthetics. Amide group. Lidocaine.

Palabras clave: Anafilaxia. Alergia. Anestésicos locales. Grupo amida. Lidocaína.

The incidence of clinical anaphylaxis during anesthesia has been estimated to be between 1 in 1250 and 1 in 10000 in several series from different countries. Amide local anesthetics have been involved in fewer than $0.6 \%$ of perioperative reactions [1]. Lidocaine is an amide local anesthetic and a class $1 \mathrm{~b}$ antiarrhythmic agent that was first synthesized in 1942 and launched in 1948 in Sweden after being authorized for human use [2]. Initially, it was used intravenously as an antiarrhythmic agent. It was also proposed that intravenous lidocaine could be potentially beneficial in perioperative settings such as relief of postoperative pain [3], prevention of propofol-induced injection pain, prevention of hyperalgesia, and bronchotracheal relaxation [4]. Lidocaine blocks the voltage-gated sodium channels that induce inhibition of both propagation of action potentials and neuronal excitability [3]. However, the underlying mechanism of intravenous lidocaine may be more complex than blockade of peripheral nerve impulses [5].

Although severe anaphylactic reactions have been reported with both amide and ester local anesthetics, amide compounds are considered to be less likely to produce such reactions than the amino-ester group. The ester group produces metabolites related to para-aminobenzoic acid, which are more likely to provoke an allergic reaction [1]. However, true allergy to amides has been reported, as has cross-reactivity within the amide group [6].

Subcutaneous challenge tests following negative skin test results (skin prick tests and intradermal tests) remain the gold standard for diagnosis of anaphylaxis induced by local anesthetics [1]. Although true allergy to amide local anaesthetics is rare, anaphylactic reaction following administration of lidocaine has been reported [7]. Nevertheless, very few cases involve anaphylactic reaction following intravenous administration of lidocaine [8].

A 70-year-old man with a history of IgE-mediated pyrazolone allergy and no other personal or family history of allergy was seen in our Allergy Unit for an adverse reaction during induction of anesthesia before undergoing retrograde intrarenal surgery. Anesthesia was induced with fentanyl $0.15 \mathrm{mg}$, lidocaine $40 \mathrm{mg}$, propofol $130 \mathrm{mg}$, and suxamethonium chloride $100 \mathrm{mg}$. Amoxicillin in combination with clavulanic acid $2 \mathrm{~g}$ had been administered 30 minutes before onset of the reaction. All these drugs were administered intravenously. Immediately after induction, the patient developed generalized erythema, tachycardia (130/min), hypotension $(58 / 32 \mathrm{mmHg})$, bronchospasm (wheeze), and labial angioedema. Phenylephrine $200 \mu \mathrm{g}$, hydrocortisone $100 \mathrm{mg} \mathrm{IV}$, and dexchlorpheniramine $5 \mathrm{mg}$ IV were administered. A few minutes after administration of these drugs, heart rate and blood pressure recovered progressively, as did wheeze and cutaneous erythema until normal values were reached. The surgery was suspended until the agent responsible for the reaction was identified. After 4 weeks, the patient was evaluated in our department. Local anaesthetics had been used in dental procedures some years previously. The results of skin prick testing were negative for latex. Prick and intradermal tests were also negative for the major determinant benzylpenicilloyl poly-L-lysine, minor determinant mix, penicillin $\mathrm{G}$, amoxicillin-clavulanate, fentanyl, propofol, suxamethonium chloride, bupivacaine, mepivacaine, and articaine. Prick testing with $1 \%$ lidocaine $(20 \mathrm{mg} / \mathrm{mL})$ was positive $(9 \mathrm{~mm})$. The single-blind controlled oral challenge with amoxicillin-clavulanate was negative. Mepivacaine and bupivacaine were both well-tolerated in the single-blind controlled subcutaneous challenge. Total serum IgE was $214 \mathrm{kU} / \mathrm{L}$. Determination of serum specific IgE for penicillin $\mathrm{V}$ and $\mathrm{G}$ yielded negative results. Specific IgE for amoxicillin was not available at the time. The tryptase value was $38.8 \mu \mathrm{g} / \mathrm{L}$ at 1 hour after the reaction and $44.7 \mu \mathrm{g} / \mathrm{L}$ at 2 hours. Baseline tryptase was $5.84 \mu \mathrm{g} / \mathrm{L}$.

The evaluation of patients with perioperative reactions must include a detailed history, in vitro determinations performed during the acute phase, and tests with all the suspected agents once the reaction has resolved $[6,9]$. Such tests include skin prick tests, intradermal tests, and drug provocation tests [9]. Provocation testing is crucial to confirm the lack of sensitization when skin tests are negative and to reassure the safe future administration of drugs [1]. Subcutaneous challenges are not risk-free, and the clinician is recommended to estimate the risk-benefit ratio for each case before initiating the test [6].

It is important to perform challenges to rule out crossreactivity with other local anesthetics, since there have been reports of patients with true allergy to amides and documented cross-reactivity within the amide group [6]. In the present case, strongly positive prick test results suggested that lidocaine was the trigger of the allergic reaction; therefore, challenge testing following negative skin test results was especially important in order to provide the patient with alternative local anesthetic agents.

Skin prick tests, including negative controls, were performed twice, thus reaffirming the result. Different production batches were used in each test. A lidocaine challenge test in this case should be considered a high-risk procedure, with the possibility of a serious reaction. To avoid placing the patient at additional risk, it was considered more ethical not to perform this challenge. The tests carried out within the patient's clinical context were deemed sufficient for diagnosis. 
There is no reliable serum test to confirm sensitivity to local anesthetics [9]. Determination of serum tryptase has proved to be more useful than that of other mast cell mediators, as in the diagnosis of anaphylaxis [10]. However, the currently available literature on allergy to lidocaine rarely refers to determination of tryptase levels [6]. In the present case, the tryptase value increased to 6 -fold that of the baseline determination.

True allergy to amide local anesthetics during induction is rare, and cases caused by intravenous administration are even rarer [8]. We believe that our findings are useful and contribute to knowledge of less suspected causes of perioperative anaphylaxis. The patient in the present study tolerated mepivacaine and bupivacaine well.

Investigation of patients with suspected allergy to local anesthetics should begin with a detailed history, followed by appropriate tests that lead to an accurate diagnosis and eventually enable prescription of safe and valid alternatives. Hypersensitivity to lidocaine should be considered in the evaluation of patients who have experienced a perioperative anaphylactic reaction.

\section{Funding}

The authors declare that no funding was received for the present study.

\section{Conflicts of Interest}

The authors declare that they have no conflicts of interest.

\section{References}

1. Mertes PM, Tajima $K$, Regnier-Kimmoun MA, Lambert M, lohom G, Gueant-Rodriguez RM, et al. Perioperative anaphylaxis. Med Clin North Am. 2010;94(4):761-89.

2. Weinberg L. Pharmacokinetics and pharmacodynamics of lignocaine: A review. World J Anesthesiol. 2015;4(2):17-29.

3. Estebe JP. Intravenous lidocaine. Best Pract Res Clin Anaesthesiol. 2017;31(4):513-21.

4. Jalota L, Kalira V, George E, Shi YY, Hornuss C, Radke O, et al. Prevention of pain on injection of propofol: systematic review and meta-analysis. BMJ. 2011;342.

5. Barletta M, Reed R. Local Anesthetics: Pharmacology and Special Preparations. Vet Clin North Am Small Anim Pract. 2019;49(6):1109-25.

6. Bhole MV, Manson AL, Seneviratne SL, Misbah SA. IgEmediated allergy to local anaesthetics: separating fact from perception: a UK perspective. Br J Anaesth. 2012;108(6):90311.

7. Chan TYK. Fatal anaphylactic reactions to lignocaine. Forensic Sci Int. 2016;266:449-52.

8. Ismail K, Simpson PJ. Anaphylactic shock following intravenous administration of lignocaine. Acta Anaesthesiol Scand. 1997;41:1071-2

9. Laguna JJ, Archilla J, Dona I, Corominas M, Gastaminza G, Mayorga C, et al. Practical Guidelines for Perioperative
Hypersensitivity Reactions. J Investig Allergol Clin Immunol. 2018;28(4):216-32.

10. Gonzalez-de-Olano D, Alvarez-Twose I. Mast Cells as Key Players in Allergy and Inflammation. J Investig Allergol Clin Immunol. 2018;28(6):365-78.

Manuscript received February 26, 2020; accepted for publication June 16, 2020.

Silvia Karina Carrión Sari Roger de flor $25,4^{\circ} \mathrm{A}$ 50017 Zaragoza, Spain E-mail: karinacarrions@hotmail.com 